\title{
PEMANFAATAN MEDIA SOSIAL MELALUI WHATSAPP GROUP FEI SEBAGAI SARANA KOMUNIKASI
}

\section{UTILIZATION OF SOCIAL MEDIA THROUGH WHATSAPP GROUP FEI AS A COMMUNICATION FACILITY}

\author{
A.Sukrillah'1a, IA Ratnamulyani ${ }^{2}$, AA Kusumadinata ${ }^{3 b}$ \\ 1,2,3 Jurusan Ilmu Komunikasi, Fakultas Ilmu Sosial dan Ilmu Politik \\ Universitas Djuanda Bogor \\ Jl. Tol Ciawi No.1 Kotak Pos 35 Bogor 16720.
}

1aKorenpondensi: Ahmad Sukrillah, Email : ahmad.sukrillah@unida.ac.id

AA Kusumadinata, Email : alialamsyahkusumadinata@gmail.com

(Diterima: 5-9-2017; Ditelaah: 28-9-2017; Disetujui: 10-10-2017)

\begin{abstract}
Technological developments have influenced many aspects of human life, not least in communication activities. WhatsApp application becomes one of the most widely used applications by various community groups in Indonesia, not least by college academics. This study aims to determine the characteristics of WhatsApp usage and to know the utilization of social media WhatsApp Group FEI as a communication media faculty of the Faculty of Islamic Economics Djuanda University of Bogor. The method used in this research is descriptive qualitative by describing, recording, analyzing and interpreting condition that currently happened or exist in Group FEI. The results showed that the use of social media WhatsApp Group in the Faculty of Economics of Islam is very large. In addition to functioning to convey information, WhatsApp Group also serves as a medium for discussion and educating, as a medium of entertainment, as well as a media to provide influence and policy making within the Faculty of Islamic Economics Djuanda University of Bogor.
\end{abstract}

Keywords: Social Media , Group FEI

\section{ABSTRAK}

Perkembangan teknologi telah mempengaruhi banyak aspek dalam kehidupan manusia, tak terkecuali dalam kegiatan komunikasi. Aplikasi WhatsApp menjadi salah satu aplikasi yang paling banyak digunakan oleh berbagai macam kelompok masyarakat di Indonesia, tak terkecuali oleh para akademisi perguruan tinggi. Penelitian ini bertujuan untuk mengetahui karakteristik penggunaan WhatsApp dan mengetahui pemanfaatan media sosial WhatsApp Group FEI sebagai media komunikasi Civitas Fakultas Ekonomi Islam Universitas Djuanda Bogor. Metode yang digunakan dalam penelitian ini yaitu deskriptif kualitatif dengan mendeskripsikan, mencatat, menganalisis dan menginterpretasikan kondisi yang sekarang ini terjadi atau ada pada Group FEI. Hasil penelitian menunjukkan bahwa pemanfaatan media sosial WhatApp Group di Fakultas Ekonomi Islam sangat besar. Selain berfungsi untuk menyampaikan informasi, WhatsApp Group juga berfungsi sebagai media diskusi dan mendidik, sebagai media hiburan, serta sebagai media untuk memberikan pengaruh dan pembuatan kebijakan di lingkungan Fakultas Ekonomi Islam Universitas Djuanda Bogor.

Kata Kunci : Media Sosial, Group FEI

A Sukrillah, IA Ratnamulyani, AA Kusumadinata. 2017. Pemanfaatan Media Sosial Melalui Whatsapp Group Fei Sebagai Sarana Komunikasi. Jurnal Komunikatio 3(2): 95-104. 


\section{PENDAHULUAN}

Perkembangan teknologi telah mempengaruhi banyak aspek dalam kehidupan manusia. Keberadaannya mempermudah setiap aktivitas yang dilakukan oleh manusia, tak terkecuali dalam kegiatan komunikasi untuk berinteraksi dengan manusia lainnya. Bermula dari keberadaan telepon yang hanya berfungsi untuk berkomunikasi jarak jauh via suara, berkembang menjadi handphone/telepon genggam yang memiliki tambahan fitur yaitu dapat mengirimkan pesan teks. Kini semakin dikembangkan dengan diciptakannya berbagai fitur/aplikasi berbasis pesan teks/messenger seperti Line, WhatsApp, Kakao Talk, hingga liteBig. Berbagai macam aplikasi messenger tersebut tidak hanya sekedar dapat mengirimkan pesan teks, namun juga dapat melakukan panggilan dan video call, bahkan dapat mengirimkan berbagai macam file seperti gambar, video, suara dan dokumen.

Kebutuhan akan berinteraksi sosial dirasa sangat penting bagi seluruh lapisan masyarakat, tidak memandang usia, jabatan dan status sosial, terutama bagi kelompok masyarakat. Suatu kelompok masyarakat/komunitas membutuhkan media sebagai sarana komunikasi untuk dapat berinteraksi dengan anggota kelompok yang lainnya tanpa harus berkumpul dan bertatap muka, seperti aplikasi messenger seperti Line, WhatsApp, Kakao Talk, hingga liteBIG.

Aplikasi WhatsApp menjadi aplikasi yang paling diminati kedua, yang digunakan oleh berbagai macam kelompok masyarakat di Indonesia, tak terkecuali oleh para akademisi perguruan tinggi seperti mahasiswa dan dosen di Universitas Djuanda Bogor. Aplikasi WhatsApp khususnya fitur WhatasApp Group dirasa ideal digunakan sebagai sarana diskusi mahasiswa dan penyebaran informasi akademik di lingkungan perguruan tinggi.
Pemanfaatan WhatsApp Group di lingkungan Universitas Djuanda Bogor sangat tinggi, tak terkecuali di Fakultas Ekonomi Islam. Dalam dua program studi yang terdiri dari empat angkatan dan terbagi dalam dua kategori kelas, yaitu regular dan karyawan, ada enam belas grup WhatsApp khusus mahasiswa Fakultas Ekonomi Islam. Selain grup mahasiswa, terdapat pula grup WhatsApp khusus yang anggotanya terdiri dari dosen dan tenaga kependidikan, baik tingkat program studi maupun tingkat fakultas.

Namun, berbeda dengan fakultas lain yang ada di lingkungan Universita Djuanda bahkan di kampus-kampus lainnya, Fakultas Ekonomi Islam memiliki grup WhatsApp yang terdiri dari ketiga komponen civitas akademika Fakultas Ekonomi Islam secara sekaligus, yaitu mahasiswa, dosen dan tenaga pendidikan yang berbaur dalam satu grup bernama Group FEI. Dengan berkumpulnya ketiga komponen tersebut memudahkan Fakultas Ekonomi Islam untuk melakukan kegiatan proses penyebaran informasi baik yang berkaitan dengan akademik, keuangan maupun kegiatan kemahasiswaan.

Atas dasar latar belakang tersebut tujuan penelitian ini adalah (1) untuk mengetahui karakteristik penggunaan WhatsApp dan (2) untuk mengetahui pemanfaatan media sosial WhatsApp Group FEI sebagai media komunikasi Civitas Fakultas Ekonomi Islam Universitas Djuanda Bogor.

\section{Tinjauan Teori}

\section{Komunikasi Massa}

Bittner menyebutkan, "mass communication is message communicated through mass medium to a large number of people", yaitu bahwa komunikasi massa adalah pesan yang dikomunikasikan melalui media massa pada sejumlah besar orang (Ngaisah, 2015). Sementara Gerbner 
mendefinisikan, bahwa komunikasi massa adalah produksi dan distribusi yang berlandaskan teknologi dan lembaga dari arus pesan yang kontinu serta paling luas dimiliki orang dalam masyarakat insustri. Jadi komunikasi massa dapat diartikan dalam dua cara, yaitu komunikasi yang dilakukan oleh media, dan komunikasi yang ditujukan kepada massa atau khalayak (Fauziah, 2012).

Fauziah (2012) menyebutkan bahwa terdapat 8 karakteristik media massa, yaitu: (1) Komunikator terlembagakan; (2) Pesan bersifat umum; (3) Komunikasinya anonim dan heterogen; (4) Media massa menimbulkan keserempakan;

Komunikasi mengutamakan isi ketimbang hubungan; (6) Komunikasi massa bersifat satu arah; (7) Stimulasi alat indra terbatas; dan (8) Umpan balik tertunda.

Fauziah (2012) juga menyebutkan bahwa terdapat 3 fungsi media massa, yaitu: (1) Fungsi informasi. Khalayak memiliki kebutuhan akan informasi dan media massa berperan menyebarkan informasi bagi khalayak. Media ini menyuguhkan beragam informasi mulai dari politik, ekonomi dan berbagai peristiwa lain; (2) Fungsi pendidikan. Media massa menyajikan beragam hal-hal yang sifatnya mendidik melalui pengajaran etika, nilai dan aturan-aturan. Nilai-nilai pendidikan tidak hanya diungkapkan secara langsung, namun divisualisasikan juga; dan (3) Fungsi memengaruhi. Fungsi memengaruhi didapat melalui tajuk, iklan, artikel dan sebagainya. Khalayak dapat terpengaruh oleh bujukan, ajakan atau diskusi yang bermaksud untuk mencapai tujuan tertentu agar khalayak tergugah.

\section{Media Sosial}

Nasrullah (2016) istilah media bisa dijelaskan sebagai sarana penyampaian pesan dari komunikator kepada komunikan. Makna sosial itu merujuk pada saling bekerja sama (co-operative work), yaitu terdapatnya karakter kerja sama atau saling mengisi di antara individu dalam rangka membentuk kualitas baru dari masyarakat. Sehingga dapat dirtikan bahwa, melalui media sosial seseorang dapat saling terhubung dengan setiap orang yang tergabung dalam media sosial yang sama untuk berbagi informasi dan berkomunikasi. Media sosial memiliki sifat yang lebih interaktif apabila dibandingkan dengan bentuk media tradisional seperti radio maupun televisi.

Adapun karakteristik media sosial menurut Nasrullah (2016), yaitu: (1) Jaringan (network). Media sosial memiliki karakter jaringan sosial; (2) Informasi (information). Informasi menjadi entitas yang penting dari media sosial; (3) Arsip (archive). Arsip mengubah cara menghasilkan, mengakses, hingga menaruh informasi; (4) Interaksi (interactivity). Pengguna bisa berinteraksi, baik di antara pengguna itu sendiri maupun dengan produser konten media; (5) Simulasi sosial (simulation of society). Pengguna media sosial bisa dikatakan sebagai warga negara digital; dan (6) Konten oleh pengguna (user-generated content). Konten sepenuhnya milik dan berdasarkan kontribusi pengguna atau pemilik akun.

Nasrullah (2016) menyebutkan ada enam kategori besar dalam pembagian jenis media sosial, yaitu:

\section{Media jejaring sosial (social networking).}

Nasrullah (2016), situs jejaring sosial adalah media sosial yang paling popular. Media sosial tersebut memungkinkan anggota untuk berinteraksi satu sama lain. Interaksi terjadi tidak hanya pada pesan teks, tetapi juga termasuk foto dan video yang mungkin menarik perhatian pengguna lain. Semua posting (publikasi) merupakan real time, memungkinkan anggota untuk berbagi informasi seperti apa yang sedang terjadi.

2. Jurnal online (blog).

Blog merupakan media sosial yang memungkinkan penggunanya untuk mengunggah aktivitas keseharian, saling mengomentari, dan berbagi, baik tautan web lain, informasi, dan sebagainya. Secara 
mekanis, jenis media sosial ini bisa dibagi menjadi dua: pertama, kategori personal homepages, yaitu pemilik menggunakan nama domain sendiri, seperti .com atau .net; kedua, dengan menggunakan fasilitas penyedia halaman weblog gratis, seperti Wordpress (www.wordpress.com) atau Blogspot (www.blogspot.com).

3. Jurnal online sederhana atau mikroblog (micro-bloging).

Tidak berbeda dengan jurnal online (blog), microbloging merupakan jenis media sosial yang memfasilitasi pengguna untuk menulis dan mempublikasikan aktivitas serta atau pendapatnya. Secara historis, kehadiran jenis media sosial ini merujuk pada munculnya Twitter yang hanya menyediakan ruang tertentu atau maksimal 140 karakter.

4. Media berbagi (media sharing).

Situs berbagi media (media sharing) merupakan jenis media sosial yang memfasilitasi penggunanya untuk berbagi media, mulai dari dokumen (file), video, audio, gambar, dan sebagainya. Beberapa contoh media berbagi ini adalah YouTube, Flickr, Photobucket, atau Snapfish.

5. Penanda sosial (social bookmarking).

Penanda sosial atau social bookmarking merupakan media sosial yang bekerja untuk mengorganisasi, menyimpan, mengelola, dan mencari informasi atau berita tertentu secara online. Dalam catatan historis, jenis penanda sosial di internet muncul pada sekitar 1996 dengan munculnya itList dan istilah social bookmarking itu sendiri muncul pada tahun 2003 dengan kehadiran situs Delicious

\section{METODE PENELITIAN}

Metode yang digunakan dalam penelitian ini yaitu deskriptif kualitatif pendekatan studi kasus. Pendekatan studi kasus ini dilakukan terfokus pada suatu kasus tertentu untuk diamati dan dianalisis secara cermat sampai tuntas (Muhlisian, 2013). Dengan kata lain peneliti akan mendeskripsikan, mencatat, menganalisis dan menginterpretasikan kondisi yang sekarang ini terjadi atau ada pada Group FEI. Peneliti melakukan observasi dan (del.icio.us). Beberapa situs social bookmarking yang popular adalah Delicious.com, StumbleUpon.com, Digg.com, Reddit.com, dan untuk di Indonesia ada LintasMe.

6. Media konten bersama atau Wiki.

Wiki merupakan situs yang kontennya hasil kolaborasi dari para penggunanya. Mirip dengan kamus atau ensiklopedi, wiki menghadirkan kepada pengguna pengertian, sejarah, hingga rujukan buku atau tautan tentang satu kata. Dalam praktiknya, penjelasan-penjelasan tersebut dikerjakan oleh para pengunjung. Artinya, ada kolaborasi atau kerja bersama dari semua pengunjung untuk mengisi konten dalam situs ini.

Menurut Nasrullah (2016), bahwa media sosial memiliki kelebihan dibadingkan dengan media konvensional, antara lain: (1) Kesederhanaan, karena sangat mudah digunakan, bahkan untuk orang yang tidak memiliki latar belakang IT pun dapat mengaksesnya; (2) Membangun Hubungan, karena menawarkan kesempatan tak tertandingi untuk berinteraksi dengan pelanggan dan membangun hubungan; (3) Jangkauan Global, dimana informasi dapat dikomunikasikan dalam sekejap, terlepas dari lokasi geografis; dan (4) Terukur, dengan system tracking yang mudah, pengiriman pesan dapat terukur dan relative waktu yang singkat.

wawancara sebagai teknik pengumpulan data dengan menggunakan participant observation, di mana peneliti akan berperan serta ke lapangan untuk mengamati objek penelitian dan aktif berinteraksi dalam kegiatan komunikasi yang terjadi dalam Group FEI. Seperti yang dikemukakan oleh Stainback dalam Sugiyono (2013), bahwa dengan wawancara peneliti akan mengetahui halhal yang lebih mendalam tentang partisipan dalam menginterprestasikan sistuasi dan fenomena yang terjadi, di 
mana hal ini tidak bisa ditemukan melalui observasi.

Analisis data kualitatif dilakukan secara interaktif dan berlangsung secara terus menerus sampai tuntas, sehingga datanya sudah jenuh. Pada saat wawancara, peneliti sudah melakukan analisis terhadap jawaban yang diwawancarai. Bila jawaban yang diwawancarai setelah dianalisis terasa belum memuaskan, maka peneliti akan melanjutkan pertanyaan kembali, sampai tahap tertentu diperoleh data yang dianggap kredibel (Sugiyono, 2013). Aktivitas dalam analisis data, yaitu data reduction, data display, dan conclusion

\section{HASIL DAN PEMBAHASAN}

\section{Karakteristik Penggunaan WhatsApp di Fakultas Ekonomi Islam}

Media sosial dimanfaatkan oleh Civitas akademika Fakultas Ekonomi Islam Universitas Djuanda Bogor, baik untuk kegiatan akademik di lingkungan kampus mupun kegiatan kesehariannya di luar kampus. WhatsApp menjadi aplikasi yang paling banyak digunakan oleh Civitas Fakultas Ekonomi Islam untuk drawing/verification, di mana setelah peneliti melakukan pengumpulan data, maka peneliti melakukan anticipatory sebelum melakukan reduksi data (Sugiyono, 2013).

Selanjutnya divalidasi untuk membuktikan hasil yang diamati sesuai dengan kenyataan dan memang sesuai dengan sebenarnya atau kejadiannya menggunakan teknik triangulasi, yaitu teknik pemeriksaan keabsahan data yang memanfaatkan sesuatu yang lain di luar data itu untuk keperluan pengecekan atau sebagai pembanding terhadap data tersebut (Agustinova, 2015). berkomunikasi satu sama lain. Selanjutnya Instagram menjadi aplikasi terbanyak kedua yang sering digunakan sebagai media berbagi foto maupun video. Lalu BBM (Blackberry Messenger) digunakan untuk aplikasi chatting. Terakhir Facebook sebagai aplikasi berbagi status kepada teman-temannya. Adapun persentase penggunaan media sosial di Fakultas Ekonomi Islam terlihat pada Gambar 1.

Gambar 1. Persentase Penggunaan Media Sosial di Fakultas Ekonomi Islam

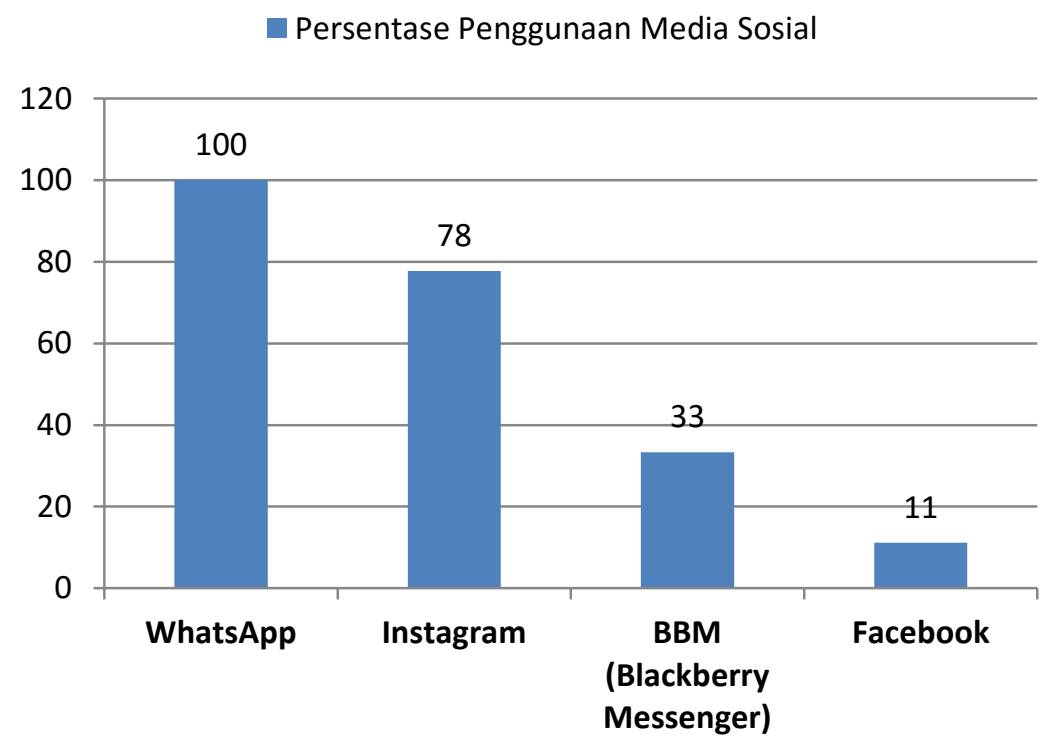


Selain digunakan sebagai aplikasi chat antar pribadi, aplikasi WhatsApp juga dapat digunakan oleh Civitas akademika Fakultas Ekonomi Islam sebagai media komunikasi kelompok yang dinamakan WhatsApp Group. Penggunaan WhatsApp Group di Fakultas Ekonomi Islam cukup besar, di mana dalam satu angkatan memilki 2 jurusan dan 2 kelompok kelas, maka dari 4 angkatan yang ada terdapat WhatsApp Group mahasiswa sebanyak 16 grup mahasiswa. Selain hal tersebut, terdapat satu grup yang anggotanya terdiri dosen, mahasiswa dan staf administrasi bernama Group FEI.

Group FEI beranggotakan 226 orang, terdiri dari 4 orang dosen program studi Ekonomi Syariah, 7 orang dosen program studi Perbankan Syariah, 2 orang tenaga administrasi, 123 orang mahasiswa program studi Ekonomi Islam, dan 103 orang mahasiswa program studi Perbankan Syariah. Dari 226 orang tersebut terbagi dalam 104 anggota berjenis kelamin lakilaki dan 122 anggota berjenis kelamin perempuan. Setiap awal tahun akademik baru anggota Group FEI mengalami pergantian, dimana mahasiswa yang sudah lulus maka akan dikeluarkan dan digantikan oleh mahasiswa baru. Mahasiswa yang telah lulus akan dimasukkan ke grup alumni Fakultas Ekonomi Islam yang bernama FASE UNIDA (Forum Alumni Syariah Ekonomi Universitas Djuanda).

Fungsi utama dibuatnya Group FEI yaitu untuk menyampaikan informasi secara meluas kepada mahasiswa dan dosen yang menjadi anggota dalam grup tersebut, seperti informasi akademik, informasi

\section{Pemanfaatan Media Sosial Whatsapp Group FEI Sebagai Media Komunikasi}

Informasi dalam Group FEI disampaikan secara aktif oleh seluruh angota grup yang ada, baik dari dosen, staf administrasi, maupun mahasiswa dan perwakilan organisasi kemahasiswaan seperti BEM dan HIMMA fakultas. Dosen sebagai tenaga pendidik memiliki peran paling penting dalam menyampaikan informasi dalam grup, baik informasi yang berkenaan dengan perkuliahan, kegiatan kemahasiswaan, maupun informasi keilmuan, baik berupa perkuliahan, informasi kegiatan kemahasiswaan, informasi hiburan, dan share ilmu pengetahuan mengenai ekonomi Islam, maupun pemberitaan nasional, serta seringkali juga terdapat informasi berupa berita bahagia maupun duka dari salah satu anggota maupun Civitas Fakultas Ekonomi Islam.

Pada dasarnya setiap informasi yang disampaikan di Group FEI pasti diterima dan dibaca oleh seluruh anggota grup, namun respon dari anggota grup akan berbeda-beda atas berbagai macam informasi yang diterima. Respon anggota grup tergantung pada siapa yang menyampaikan informasi tersebut, dimana ketika dosen yang menyampaikan maka otomatis responnya akan baik dan banyak yang menanggapi. Namun berbeda, ketika mahasiswa yang menyampaikan informasi, respon dari anggota grup yang lain biasa saja dan tanggapannya kurang. Topik atau isi informasi yang disampaikan juga menentukan respon dari anggota yang lain, dimana ketika ada informasi akademik maka responnya biasa dan hanya dibaca saja oleh anggota yang lain, akan tetapi ketika ada informasi yang bersifat himbauan atau pemberitahuan maka responnya akan baik dan banyak yang akan menanggapi. Selain dua hal tersebut, respon dari setiap informasi yang disampaikan di Group FEI tergantung kepada masing-masing anggota grup, karena hanya ada beberapa orang saja yang memang aktif menanggapi setiap informasi yang masuk, namun pada dasarnya semua anggota grup pasti membaca pesan yang masuk ke dalam Group FEI.

\section{Informasi bagi Civitas FEI}

berita ekonomi dan perbankan, ataupun acara kajian dan seminar ekonomi Islam. Tenaga administrasi memiliki wewenang untuk memberikan informasi jadwal perkuliahan dan pelayanan mahasiswa berkenaan dengan kegiatan akademik di Fakultas Ekonomi Islam.

Pada saat ini Fakultas Ekonomi Islam selain menyampaikan informasi kegiatan akademik dan perkuliahan melalui media WhatsApp Group, juga masih 
mempertahankan penyampaian infomasi melalui Mading (majalah dinding). Namun penyebaran informasi melalui Group FEI sangat efektif jika dibandingkan dengan penyebaran informasi yang ditempel di mading. Di era teknologi seperti saat ini hampir setiap mahasiswa sangat mengandalkan gadget dan smartphone-nya untuk mendapatkan informasi, karena melalui Group FEI informasi yang dikirim akan

\section{Sarana Diskusi dan Mendidik Civitas FEI}

Media komunikasi di lingkungan akademisi perguruan tinggi, setiap komunikasi dan informasi yang disampaikan bersifat mendidik, baik oleh dosen maupun mahasiswa. Selain hal tersebut juga Group FEI difungsikan sebagai media diskusi untuk membahas berkenaan dengan aktifitas perkuliahan dan ilmu pengetahuan tentang ekonomi Islam, serta membahas info terupdate dan yang sedang booming di negeri ini, seperti masalah politik, perkembangan ekonomi, dan sebagainya.

Diskusi dapat bersumber baik dari suatu informasi yang disengaja untuk memancing diskusi, maupun dari informasi biasa yang ditanggapi secara berkelanjutan sehingga terjadinya suatu diskusi. Dalam hal ini dosen berperan aktif untuk mengajak para mahasiswa berdiskusi

\section{Media Hiburan bagi Civitas Fakultas Ekonomi Islam}

Sebagai salah grup komunikasi yang berada di lingkungan akademik, komunikasi dalam Group FEI tidak selalu serius dan kaku. Sesekali terdapat pesan yang mengandung hiburan, baik oleh mahasiswa maupun dosen. Pesan hiburan yang disampaikan dalam Group FEI dapat berupa konten foto/gambar maupun video yang mengandung unsur kelucuan. Seringkali juga pesan hiburan tersebut dapat berupa artikel, broadcast, maupun posting cerita yang memancing gelak tawa dan kelucuan.Dengan adanya komunikasi yang bersifat hiburan, interaksi antar anggota langsung tersampaikan kepada seluruh anggota grup. Walaupun pada saat ini minat membaca mahasiswa untuk melihat informasi di mading sangat sedikit, namun penyampaian informasi melalui mading juga harus tetap dipertahankan dan dilestarikan. Namun terkadang informasi penting yang disampaikan dalam Group FEI tertimpang tindih oleh informasi lainnya ataupun oleh komentar dari anggota grup yang lain.

tentang ilmu pengetahun maupun suatu fenomena yang sedang terjadi. Adapun baik staf administrasi, mahasiswa, maupun organisasi kemahasiswaan seperti BEM dan HIMMA hanya sesekali saja dalam memulai diskusi.

Dosen juga berperan penting dalam menyampaikan pesan yang mendidik kepada anggota yang lain khususnya mahasiswa, baik dalam menentukan topik pembahasan diskusi maupun dalam menyampaikan argumennya. Sebagai tenaga pendidik, dosen memiliki wawasan yang lebih luas dan pengalaman hidup yang banyak, sehingga diwajibkan untuk mengajarkan hal-hal yang baik serta menyampaikan pesan yang mendidik bagi mahasiswanya.

dalam Group FEI menjadi lebih cair. Di Fakultas Ekonomi Islam sendiri hubungan antara mahasiswa dan dosen sangat akrab dan dekat sekali, serta kesenjangan tidak terlalu terasa, sehingga mahasiswa tidak sungkan-sungkan untuk share hal-hal lucu di grup. Walaupun tidak dapat dipungkiri kesenjangan tersebut ada dan begitu terasa, terlebih bagi anggota dan mahasiswa baru, sehingga masih merasa malu-malu untuk ikut aktif berkomunikasi di Group FEI. Namun ada juga mahasiswa yang merasa sudah dekat dengan dosen, 
sehingga berani untuk share hal-hal lucu tanpa ragu dan malu-malu.

Namun terkadang pesan hiburan tidak selamanya dapat diterima dengan baik oleh setiap anggota, baik ketika pesan tersebut mengandung unsur yang kurang pantas ataupun disampaikan pada momen yang kurang pas. Ketika ada pesan atau informasi hiburan yang dipandang kurang pantas atau menyalahi etika, maka anggota tersebut langsung ditegur khususnya oleh dosen, untuk selanjutnya diluruskan dan kembali membahas hal-hal yang baik dan bermanfaat. Menyampaikan hiburan pada waktu yang kurang tepat juga terkadang mendapat teguran baik dari dosen maupun dari anggota yang lain. Seringkali, tanpa ditegur secara langsung pun biasanya anggota tersebut mengakui kesalahannya, juga biasanya anggota yang lain menegur melalui personal message (pesan secara pribadi).

\section{Kebijakan bagi Civitas FEI}

Group FEI tidak ada tata tertib atau aturan secara tertulis mengenai penyampaian pesan apapun. Namun kembali kepada masing-masing pribadi anggota khususnya mahasiswa, karena pada dasarnya mereka tahu batasan-batasan yang masih dianggap wajar, serta sopan dan beretika. Setiap anggota yang ingin menyampaikan informasi diharapkan untuk menyaring konten-konten yang akan dikirim ke grup, karena pesan apapun yang disampaikan diharapkan bersifat mendidik dan bermanfaat. Sebenarnya dalam logo Group FEI sendiri terdapat kata-kata atau slogan yang bisa dijadikan acuan dalam penggunaan berkomunikasi di Group FEI ini, yaitu: official group, FEI only, for sharing information, updates and news (informasi terbaru dan berita), no trolling, no spamming, no flamming, no junking, dan post great words.

\section{KESIMPULAN DAN IMPLEMENTASI}

\section{Kesimpulan}

1. Karakteristik penggunaan WhatsApp di Fakultas Ekonomi Islam Universitas Djuanda Bogor terdiri dari dosen, mahasiswa dan staf administrasi yang dinamakan Group FEI, beranggotakan 226 orang, terdiri dari 4 orang dosen program studi Ekonomi Syariah, 7 orang dosen program studi Perbankan Syariah, 2 orang tenaga administrasi, 123 orang mahasiswa program studi Ekonomi Islam, dan 103 orang mahasiswa program studi Perbankan Syariah.

2. Pemanfaatan media sosial WhatsApp Group FEI di lingkungan Fakultas Ekonomi Islam yaitu sebagai: penyampaian informasi sivitas Fakultas Ekonomi Islam; sarana diskusi dan mendidik sivitas Fakultas Ekonomi Islam; hiburan bagi sivitas Fakultas Ekonomi Islam dan penyampaian kebijakan bagi sivitas Fakultas Ekonomi Islam.

\section{Implementasi}

Pemanfaatan Group FEI di lingkungan akademik Fakultas Ekonomi Islam Universitas Djuanda Bogor diharapkan mampu sebagai diskusi secara rutin dalam Group FEI, selain untuk menjalin interaksi dan hubungan yang semakin erat antar anggota, juga untuk melihat tingkat pengetahuan dan wawasan dari para mahasiswa dalam menyampaikan argumentasinya, khususnya dalam berkomunikasi secara non verbal. 


\section{DAFTAR PUSTAKA}

Agustinova, Danu Eko. 2015. Memahami Metode Penelitian Kualitatif. Yogyakarta (ID): Calpulis.

Fauziah, Ririn. 2012. Minat Masyarakat dalam Menggunakan Media Massa (Studi Deskriptif di Komplek Banjar Agung Indah, Kota Serang [Skripsi]. Serang : Universitas Sultan Ageng Tirtayasa Serang.

Muhlisian, Asep Achmad. 2013. Analisis Kesalahan Terjemahan Bahasa Jepang Yang Terdapat Dalam Karya Ilmiah S2 Universitas Pendidikan Indonesia [Tesis]. Jakarta : Universitas Pendidikan Indonesia Jakarta.

Nasrullah, Rulli. 2016. Media Sosial Perspektif Komunikasi, Budaya, dan Sosioteknologi. Bandung (ID): Simbiosa Rekatama Media.

Ngaisah, Siti. 2015. Dampak Komunikasi Massa pada Khalayak (Studi Deskriptif Kualitatif Tayangan Visualisasi Tubuh Perempuan di Acara Late Night Show Trans TV pada Mahaiswa Ilmu Sosial dan Humaniora UIN Sunan Kalijaga Yogyakarta [Skripsi]. Yogyakarta : UIN Sunan Kalijaga Yogyakarta.

Sugiyono. 2013. Metode Penelitian Kombinasi (Mixed Methods). Bandung (ID) : Alfabeta. 
